\title{
A quantitative history of the U.S. Clean Water Act's jurisdiction
}

This manuscript has been submitted for publication in WIREs-Water. Please note that this version has not undergone peer review and has not been formally accepted for publication. Subsequent version of this manuscript may have slightly different content. If accepted, the final version of this manuscript will be available via the Peer Reviewed Publication DOI link on the right-hand side of this webpage. Please contact the corresponding author with any questions or concerns.

\section{Authors:} Riley Walsh

O'Neill School of Public and Environmental Affairs Indiana University rkwalsh@indiana.edu

Adam S. Ward *

O’Neill School of Public and Environmental Affairs Indiana University

* Corresponding author

418 MSB-II

Bloomington, IN 47405

Email: adamward@indiana.edu

Phone: 812-865-4820

\section{Abstract}

The Clean Water Act (CWA) is the primary federal mechanism by which the physical, chemical, and biological integrity of streams, lakes, and wetlands are protected in the U.S. The CWA has evolved considerably since its initial passage in 1948, including explicit expansions and contractions of jurisdictional scope through a series of legislative actions, court decisions, and agency rules. Here, we provide a practical summary of the CWA's evolution, detailing the major updates or revisions and their circumstances. Additionally, we identify the jurisdictional scope of the law for rivers, lakes, and wetlands based on the language used and implementation by the agencies during the same time period. While the rulemaking process does not commonly include a translation of language to on-theground implications, quantifying the (un)certainties and magnitude of changes is an important perspective to understanding the implications of environmental regulation development, litigation, and enforcement. Thus, we translate the enforcement norms and definitions into quantitative estimates for water bodies in the Wabash River Basin as a demonstration of the spatial realization of changing environmental regulations. 


\section{Graphical/Visual Abstract and Caption}

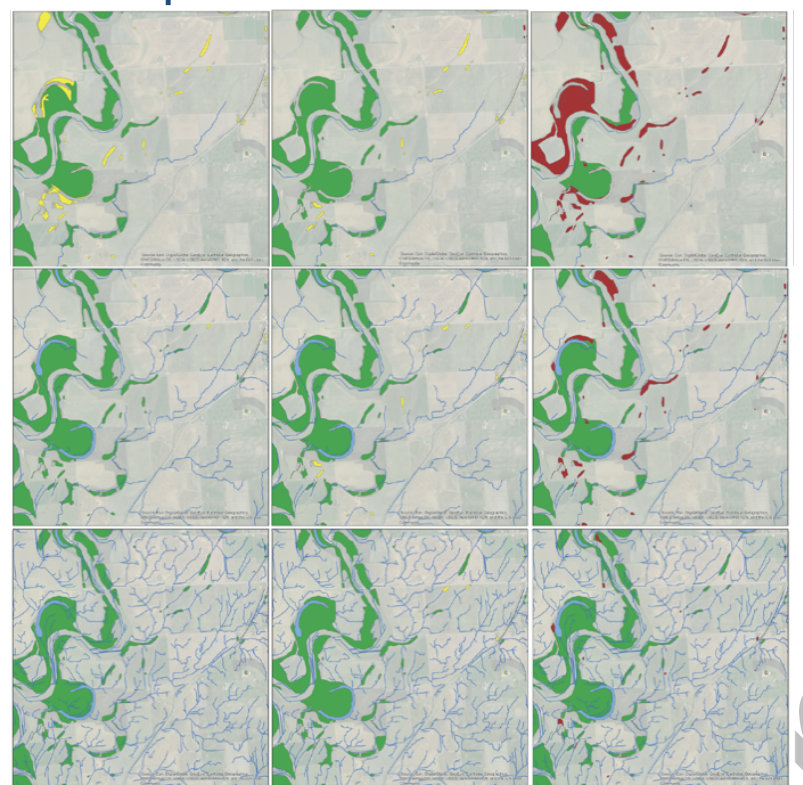

The geographic extent of U.S. federal protections for river, lakes, streams, and wetlands under the Clean Water Act has evolved considerably since 1948 (modified with permission from [1]). 


\section{INTRODUCTION}

Interpretation and enforcement of the Clean Water Act has evolved since its origin as the 1948 Federal Water Pollution Control Act. A series of Supreme Court cases, federal guidance, and rulemaking have sought to answer the fundamental issue of which waters are federally protected. Debate about which streams, lakes, and wetlands are regulatory (hereafter the "Waters of the United States", or WOTUS) has regularly arisen since the term WOTUS was included in the 1972 amendments to the Federal Water Pollution Control Act (commonly the Clean Water Act, CWA) [2]. Federal protections provided via the Clean Water Act (e.g., permit requirements to dredge, fill, or discharge pollutants) extend only to those waters classified as WOTUS, making it essential to understand the geographical extent of federal protections. Despite the clear importance of understanding which waters are federally regulated, numerous court decisions and agency recommendations have not produced a robust definition required for proactive and efficient regulation. Moreover, while several comprehensive reviews discuss the evolving legal definition of WOTUS [e.g., $3,4]$, these do not translate to a practical assessment of how the scope of the Clean Water Act is changing on the landscape.

Our objective in this study is to document the evolving spatial protections afforded to U.S waters from 1948 to present. We examined how the implementation of the Clean Water Act has evolved through a series of amendments, Supreme Court cases, executive orders, and agency rules during its history. Based on the evolution of the regulatory process, we quantified the impact these changes have had on the ground, detailing the miles of stream, and acres of lake and wetland regulated from 1948 to present day, taking the Wabash River basin as a case study. We highlight key decision-points and their on-the-ground consequences, and use our scientific understanding to attribute quantitative bounds to the vague and uncertain terminology. This quantitative history of WOTUS is the first of its kind and serves to document the co-evolution of enforcement with our understanding of hydrological systems, detail trends in regulatory scope, and provide historical context for ongoing legal cases surrounding the enforcement of the Clean Water Act [5-7].

Four periods in the evolving enforcement of the Clean Water Act

The jurisdictional history of what we commonly call the Clean Water Act can be subdivided into four distinct time periods, each marked by different challenges and legal objectives. From 1948 to 1972 the act targeted water pollution without a meaningful threat of enforcement. A series of amendments strengthened the regulation, paving the way for the critical 1972 amendments. The decade following the 1972 amendments saw the newly formed Environmental Protection Agency in disagreement with the US Army Corps of Engineers, with both agencies seeking to draw jurisdictional lines to best satisfy their own missions and goals. The agencies came into agreement in 1982, and jointly refined jurisdictional boundaries in response to a series of Supreme Court decisions, concluding with Rapanos v. United States in 2006. In the present era, the agencies strive to best interpret Rapanos, and new rules have been established aimed at resolving uncertainty produced by broad judicial language.

\section{A BRIEF HISTORY OF THE CWA AND ITS EVOLUTION}

\subsection{Pre-Clean Water Act (1948-1972)}

The Federal Water Pollution Control Act became law in 1948 [8] and was the first law that aimed to protect human health by requiring the abatement of pollution to waterways. Only "interstate waters" were regulated at this time, and only that pollution which "endanger[ed] the health or welfare of persons in a State other than that in which the discharge originate[d]" was subject to provisions of the law. Given the difficulty of confidently attributing illnesses to a specific polluter, no legal action was witnessed under this initial version of what we now call the Clean Water Act [9].

Amendments in 1961 expanded these protections to intrastate waters [10], and in 1965 the first water quality criteria were established [11]. These criteria required states to develop federally approved water quality standards for interstate waterways, and abate any pollution exceeding those thresholds [9]. Jurisdiction was guided solely by the legislature, with no clear definitions of which waters were regulatory. For a water to fall under the act's purview, damage to human health or failure to meet water quality criteria in select waterways needed to be evidenced. 


\subsection{Learning Agency Teamwork (1972-1982)}

The Federal Water Pollution Control Act [8] provided the foundation for water protections in the United States, laying the groundwork for stronger legislation. It was entirely rewritten in 1972 in an amendment that rebranded the legislation as the Clean Water Act (CWA) [2]. The amendment laid out several ambitious goals for US waters, including the elimination of pollutant discharge to navigable waterways by 1985 [12], a goal which still has not been realized [e.g., 13,14]. While providing more concrete federal rules, the newly written CWA also emphasized autonomy of the states, asserting an intent to ensure that states maintain the right to "prevent, reduce, and eliminate pollution" [2]. The amendment, which came on the heels of the Cuyahoga River fire, had strong bipartisan support. When President Nixon vetoed the amendment due to its "unconscionable \$24 billion price tag" [15], both Congressional Democrats and Republicans united to override the veto and pass the legislation (House Vote No. 459; Senate Vote No. 571, both in 1972).

The CWA expanded upon the regulatory framework pioneered in 1965, implementing more comprehensive water quality standards. The act required permitting of point source discharges to navigable waters and provided the federal government the power to set effluent limitations for point sources in cases where discharges would "interfere with the attainment or maintenance of [...] water quality" [2].

As written, the CWA has jurisdiction over "navigable waters," which are defined as "waters of the United States including the territorial seas" (commonly WOTUS). The introduction of this vague legislative definition intentionally left room for interpretation by the U.S. Army Corps of Engineers (USACE) and the newly formed U.S. Environmental Protection Agency (USEPA). Notably, this marked a shift away from complete legislative control, with a transfer of autonomy and decisionmaking to the executive branch agencies.

In 1973, the USEPA proposed a refined definition of WOTUS to define which waters were subject to Clean Water Act regulations [16]. Their definition included navigable waters, tributaries to navigable waters, and interstate waters. Additionally, waters meeting certain criteria also received protections, including waterways utilized for recreation and industrial purposes, and those from which fish and shellfish are taken and sold. These conditions applied to streams and lakes, but wetlands were not regulated by the USEPA at this time.

In contrast and coincident in time, the USACE argued that "navigable waters" were all waters "subject to the ebb and flow of the tide" and those that are presently, have been historically, or may be in the future utilized for interstate commerce [17]. These conflicting agency definitions increased the confusion surrounding WOTUS and enforcement. Following Natural Resources Defense Council v. Callaway [18], the USACE expanded its definition of which streams and lakes were regulated, and considered certain wetlands a type of jurisdictional water for the first time $[19,20]$.

In 1980, the USEPA authored a revision to their rule [21], which the USACE signed onto two years later. This harmonized definition of WOTUS borrowed from each agency's previous rule. At this time, WOTUS was understood to include waters used for commerce, recreation, fishing and industry, tributaries to those waters, and wetlands adjacent to regulated lakes and streams.

\subsection{Wetlands and the Supreme Court (1982-2005)}

The agencies' decision to consider wetlands as WOTUS prompted a series of Supreme Court cases aimed at determining if and to what extent the legislature intended wetlands to fall under CWA jurisdiction. Wetlands are not commonly considered navigable bodies of water and tend to offer less recreational opportunity than rivers and lakes. However, research was increasingly demonstrating the importance of wetlands to critical services supporting water quality and ecosystems traditionally regulated under the CWA [e.g., 22,23].

In 1985 the Supreme Court ruled that wetlands play a crucial role in maintaining water quality and are "inseparably bound up with" jurisdictional waters [24]. On this basis, the Supreme Court maintained 
that all wetlands adjacent to a jurisdictional water should be considered WOTUS. Consequently, the agencies updated their rules in 1986 to clarify protections for streams and wetlands [25]. For the first time, the agencies defined regulated streams as those bearing a defined bed, banks, and ordinary high water mark [25]. Importantly, an ordinary high water mark is a field indicator that could include several types of evidence of flow, including geomorphic shelving, debris, and visible moisture. Under the 1986 rule, an ordinary high water mark indicated the presence of water at a significant enough duration to merit classification as a stream, even if the streambed in question was dry at the time of investigation. All wetlands "adjacent" to regulated streams and lakes were also included in the definition of WOTUS, with adjacency further defined to include "bordering, continuous, or neighboring" [25].

In 2001, WOTUS issues were once again before the Supreme Court, this time to determine the legality of the agencies' "Migratory Bird Rule," which categorized the movement of migratory birds across state boundaries as interstate commerce [25]. This rule effectively brought all waters used by migratory birds under CWA protection via the Commerce Clause, regardless of their adjacency to traditionally regulated waters. In Solid Waste Agency of Northern Cook County v. U.S. Army Corps of Engineers (commonly 'SWANCC'), the Supreme Court ruled that migratory bird use could not be the sole reason that a waterway was considered jurisdictional under the CWA, striking down the rule [26]. It was reasoned that in cases where agency legal interpretation stretches Congressional authority, it needs to be clear that those legal actions were originally intended by Congress [26]. It was decided that the language of the CWA did not indicate that isolated wetlands and waterways with no obvious outlet to WOTUS should be considered jurisdictional based solely on migratory bird use. This exertion of judicial power over agency decisions placed clear limits on the extent of CWA protections for the first time.

In 2006, the Supreme Court revisited wetland jurisdiction once again. Rapanos v. United States [27] involved a developer who filled three wetlands adjacent to manmade ditches that flowed intermittently and ultimately drained into a jurisdictional stream. Since the wetlands themselves were not immediately adjacent to WOTUS but were connected via an intermittently flowing and manmade ditch, federal protection under the CWA was not clearly established. In a 4-1-4 decision, the Supreme Court did not reach a majority decision about whether the wetlands in question were WOTUS. Despite this, 5 of the 9 justices agreed to overturn the ruling of the lower court, sending back the case for reevaluation. As a result, despite differing jurisdictional interpretations, opinions authored by both Justice Kennedy and Justice Scalia set legal precedent.

Justice Scalia was joined by three other justices in defining WOTUS as "relatively permanent" bodies of standing or flowing water normally called "streams, oceans, rivers, [and] lakes". "Ephemeral streams," which only flow during rain events, were excluded. Scalia posited that wetlands adjacent to WOTUS should also be WOTUS if a "continuous surface connection" exists. Lacking a surface connection, he argued, wetlands should not be regulated.

Justice Kennedy authored an independent opinion that wetlands are WOTUS if they possess a "significant nexus," -- or meaningful connection -- to waters that are navigable or can be made so. Kennedy also emphasized that wetlands should not be examined in isolation, but in the context of the surrounding landscape. He argued that wetlands should be considered jurisdictional if they impact the quality of navigable waterways either "alone or in combination with similarly situated lands in the region". For example, if a network of wetlands improves downstream water quality, none of those wetlands should be removed, even if the elimination or degradation of one in isolation does not produce a noticeable change.

Ultimately Rapanos v. United States marked the end of an era that tested the unified rules promulgated by the agencies and disputed in the courts. Power shifted to the judicial branch as agency rules were successfully challenged and found contrary to the legislature's intent. In his Rapanos v. United States concurring opinion, Justice Roberts lamented the fact that "the Corps and the EPA would have enjoyed plenty of room to operate in developing some notion of an outer bound to the reach of their authority" following SWANCC, further stating that the case could have been readily avoided [27]. This era closes with the judiciary tasking the agencies to develop strategies for 
implementation and refined definitions of upper jurisdictional bounds ${ }_{2}$ and creating the need for "significant nexus" and "continuous surface connection" tests.

\subsection{The Post-Rapanos Era (2006-Present)}

Rapanos v. United States led to confusion amongst regulators and the regulated community about which wetlands should be considered WOTUS. Lacking one unified rule, the agencies released a guidance document in 2008 which aimed to clarify the ruling [28]. The agencies indicated any wetland with a significant nexus to navigable waters should be considered jurisdictional, at any distance from the receiving water.

In 2015, with the support of the Obama administration and building upon a comprehensive assessment of the science [29], the agencies finalized the Clean Water Rule. This rule set clear, quantitative standards outlining when significant nexus tests needed to be performed. Lakes and wetlands were considered jurisdictional if they were within 100 feet of WOTUS, within the 100-year floodplain and 1,500 feet of WOTUS, or within 1,500 feet of "traditionally navigable" waters [30]. Significant nexus tests were required for other lakes and wetlands within the 100-year floodplain of traditionally navigable WOTUS, or within 4,000 feet of WOTUS and interstate waters. Any waterbodies falling outside these criteria were exempt from permitting and no significant nexus test would be required.

The Clean Water Rule immediately faced litigation and was stayed nationwide by the Sixth Circuit Court of Appeals less than two months after its promulgation [31]. This reverted the most recent agency regulation back to their 1986 rules and 2008 guidance. Three years later, however, a Supreme Court case determined that the Court of Appeals did not have authority to stay the Clean Water Rule in the first place, restoring its implementation [32].

The agencies, now guided by the Trump administration, quickly responded to this ruling by suspending the Clean Water Rule for two years [33]. However, later that year the South Carolina District Court placed an injunction on the agencies' delay [6]. The injunction revived the Clean Water Rule in 26 states, resulting in a patchwork of regulation where 24 states operated under the 2008 guidance and the other 26 operated under the Clean Water Rule. In several cases, a single agency district was responsible for simultaneously enforcing both rules across different regions. After years of back-and-forth, the rule was formally repealed in 2019 [34].

In response to an executive order [35], the agencies finalized a new rule in 2020 entitled the Navigable Waters Protection Rule (NWPR) [36]. Much like the Clean Water Rule, the stated goal of this rule was to increase predictability and clarify the scope of WOTUS. In a departure from the longstanding 1986 precedent [37], the NWPR redefined jurisdictional streams as those with perennial or intermittent flow, explicitly excluding those with ephemeral flow. Since 1986, streams with bed, banks, and evidence of flow had been considered jurisdictional irrespective of observed flow frequency. The rule also determined that only lakes and wetlands immediately adjacent to, or touching WOTUS were WOTUS themselves, again departing from 1986 precedent allowing for a wider jurisdictional buffer to define adjacency. 


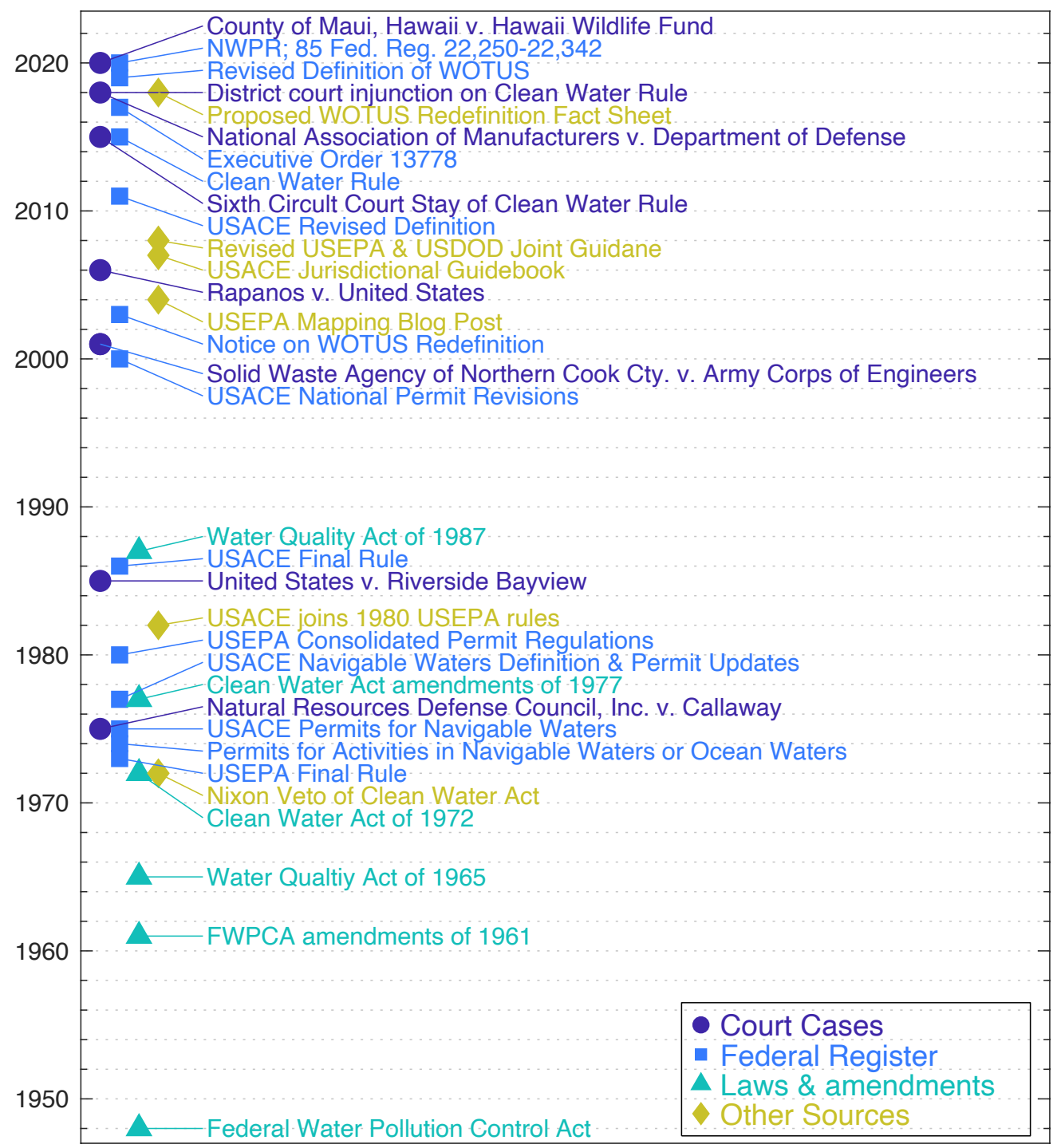

Fig. 1. Timeline of court cases, publications in the Federal Register and Code of Federal Regulations, legislation and amendments, and complementary documentation germane to the evolving definition of the jurisdictional scope of the Clean Water Act. Taken together, these events, decisions, and documents define the Waters of the U.S. and form the basis upon which waters receive federal protections. Note the documents and decisions above are a fraction of the available literature that was reviewed, but provide an overview of significant events that have defined the evolving scope of the Clean Water Act.

\section{THE EVOLVING JURISDICTIONAL SCOPE OF THE CLEAN WATER ACT} 3.1 Changing regulatory definitions and their translation to geographical definitions To quantify the changes in jurisdictional scope since the Federal Water Pollution Control Act was passed in 1948 [8], we systematically reviewed the language in agency rules and guidance, executive orders, Supreme Court cases, legislation, and studies about CWA jurisdiction from 1948 to present $[2,8,21,24,26,27,29,31,32,35-37,10,38-47,11,48-57,15,58-67,16-20]$. During this review we noted any qualitative and quantitative descriptors that were used to define the scope of which waters were 
jurisdictional (Fig. 1). Notably, we tracked the various characteristics of lakes, rivers, and wetlands that pertain to their jurisdictional status (e.g., inter- vs. intrastate, perennial vs. ephemeral, natural vs. man-made). On this basis, we classified jurisdictional waters as either "definitively," "possibly," "conditionally," or "not" jurisdictional. "Definitively" jurisdictional waters included those explicitly specified as jurisdictional. For example, traditionally navigable rivers were classified as "definitively" jurisdictional because this is explicitly articulated in the original legislation. Similarly, "not" jurisdictional waters included all waters explicitly excluded by a rule or decision. For example, when the Clean Water Rule was enacted, all waters that failed to fall under the definition of WOTUS or to require a significant nexus test were considered "not" jurisdictional.

However, WOTUS were not always defined explicitly enough to allow for "definitively" or "not" jurisdictional classification, so two separate categories were also designed to account for different types of uncertainty. For waters that we expect would be determined jurisdictional based on our interpretation of the language used in rulemaking and decisions, we defined the classification of "possibly" jurisdictional waters. This typically reflects a generous reading of the language, defining a maximum geographic scope of regulations (in contrast to "definitively" jurisdictional waters, which are a more geographically conservative lower boundary). For example, decades of WOTUS definitions have considered streams with a bed, banks, and ordinary high water mark jurisdictional. Since this demarcation is subject to individual interpretation in the field, it cannot be easily quantified. In this and other situations, scientific judgement and literature review informed a conservative upper and lower bound [1]. Finally, we identified several "conditionally" jurisdictional waters. These waters were considered WOTUS if specific criteria were met. For example, waters that would be jurisdictional only if they passed a significant nexus test were included in this category.

Finally, to translate evolving definitions and legal bases into their on-the-ground implications, we applied these definitions across the Wabash River Basin. This analysis adds a temporal dimension to an existing case study that has been used to document the impact of regulatory decisions on CWA enforcement [1]. In the cases where quantifiable definitions were explicit in regulations, these were implemented directly. For example, the 2015 Clean Water Rule defined quantitative buffer areas around regulated streams. Other rules, such as those promulgated by the USACE in 1975 [19], regulated water bodies that could easily be identified using attribute data, like impoundments. We also used the 100-yr floodplain defined by the National Flood Hazard Layer for cases where regulatory decisions were conditioned on this floodplain extent. In other cases, vague language could not be easily quantified, so proxies were used. For example, several iterations of the WOTUS definition regulate buffers around "navigable waters" that are, have been, or could be used for interstate or foreign commerce. Section 10 of the Rivers and Harbors Act also regulates those waters [68], so agency lists of Section 10 waters were used as a conservative lower limit if no further agency guidance was provided. While perennial or intermittent streams should be regulated under the 2020 rule, we used the same high and low estimations for where an ordinary high water mark might be observed to ensure a conservative estimate of the change, and as a result, data reflected here may overestimate actual protections [after 1]. For wetlands, the regulatory term "Adjacent" was assumed to only apply to those wetlands and lakes actually touching or intersecting regulated waters unless otherwise specified in the regulation. When adjacency was defined as "bordering, continuous, or neighboring" in 1986 [25], we implemented a buffer around regulatory streams and rivers. Although different buffers have been used across different agency districts, we used the 500 -ft buffer suggested by a U.S. Government Accountability Office review of agency practices [69] to define waters that were possibly jurisdictional.

\subsection{Temporal evolution of jurisdictional scope}

The changing definitions for WOTUS have overall expanded protections for rivers, lakes, and wetlands (Fig. 2-4; Table 1), but uncertainty remains. From 1948 to 1972 waters were only conditionally or not regulated since pollution had to be linked to a negative human health impact and even then, only across interstate waters. Jurisdiction and uncertainty both increased immediately following passage of the 1972 CWA. Almost all waters could be protected under the act if certain conditions were met because the broad definition of WOTUS placed no clear limit on jurisdiction, necessarily encompassing all different agency interpretations past that point. 
Uncertainty in interpretation is pronounced after 1986 due to the qualitative "ordinary high water mark" determination used to identify the upward limit of jurisdiction in the headwaters. Over $89 \%$ of global stream miles are headwaters [70,71], and all or some of these may have been identified as WOTUS depending upon field interpretations. Even though most stream miles are headwater streams, these waterways are the ones where regulatory uncertainty is highest. Thus, we find high uncertainty since we do not know precisely where agency staff might place the upward limit of the ordinary high water mark in the headwaters. Lake and wetland jurisdiction are heavily influenced by how far into the headwaters WOTUS extend, so uncertainty in stream jurisdiction is propagated forward into lake and wetland jurisdiction [1].

Compared to large fluctuations between 1948 to 1986, the miles and acres of WOTUS remain relatively constant from 1986 to present day (Fig. 2-4). Neither the 2015 Clean Water Rule nor the 2020 NWPR impacted the miles of regulated streams for the purposes of this analysis. Both rules also successfully reduced regulatory uncertainty over which lakes and wetlands are considered WOTUS through different strategies. The 2015 Clean Water Rule expanded protections and slightly increased the acres of non-jurisdictional wetlands, thereby reducing the total acreage in possibly and conditionally jurisdictional lakes and wetlands. The 2020 NWPA contracted protections to only those lakes and wetlands immediately adjacent to a regulated stream, in contrast to the Clean Water Rule, which assigned a buffer based on the best available science [29]. Consequently, this increased the acres of non-jurisdictional lakes and wetlands (Fig. 3-4), eliminating all conditionally jurisdictional waters which would be subject to a significant nexus test under previous rules. 


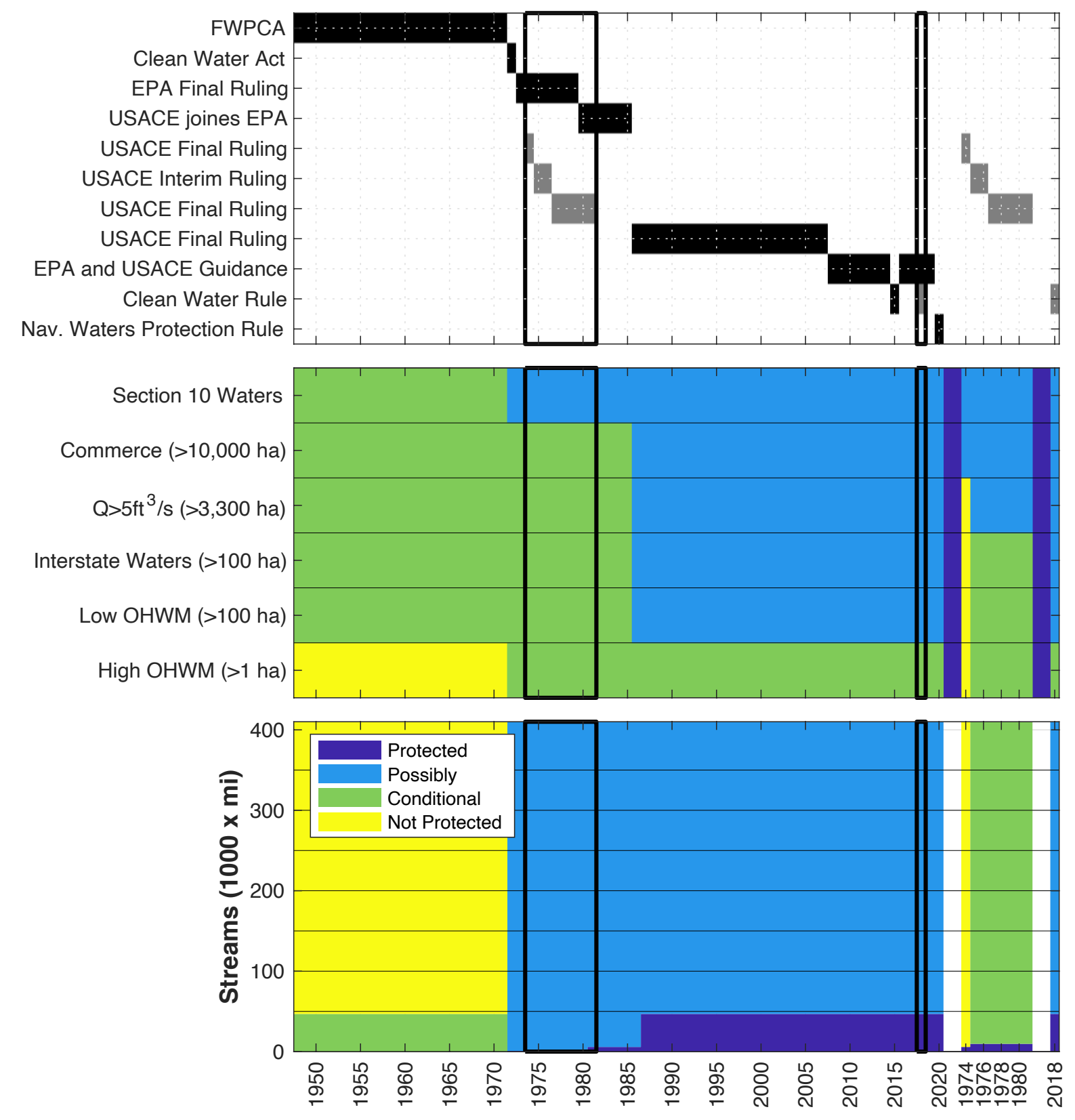

Fig. 2. Timeseries of actively enforced regulations and/or guidance (top), definitions used to designate jurisdictional status for streams (middle), and 1000s of miles of jurisdictional streams within the Wabash River Basin. Colors panels denote the jurisdictional status as a function of applicable definitions (middle) and the spatial extent of waters in each category (bottom). 


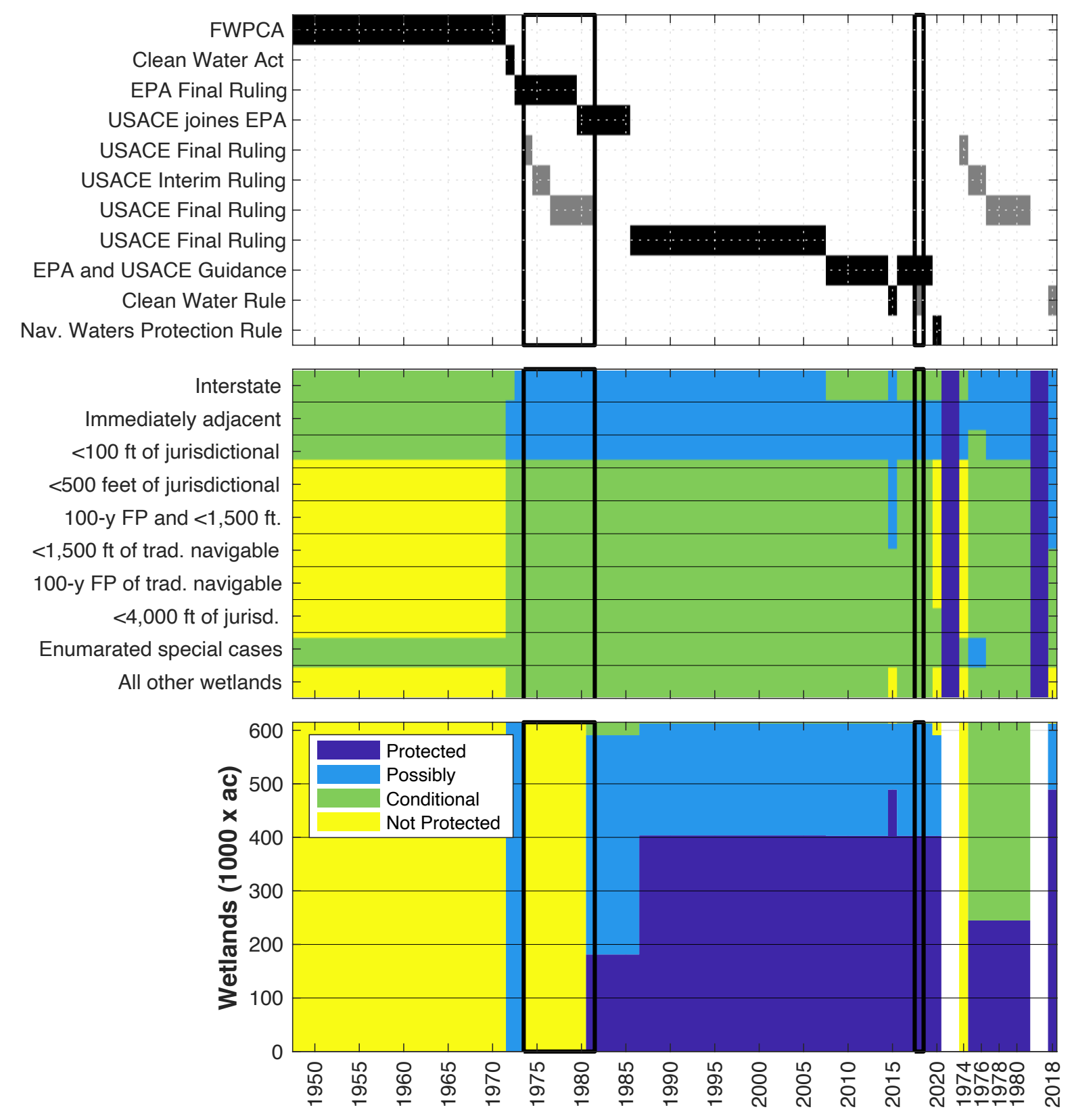

Fig. 3. Timeseries of actively enforced regulations and/or guidance (top), definitions used to designate jurisdictional status for wetlands (middle), and 1000s of acres of jurisdictional wetlands within the Wabash River Basin. Colors panels denote the jurisdictional status as a function of applicable definitions (middle) and the spatial extent of waters in each category (bottom). 


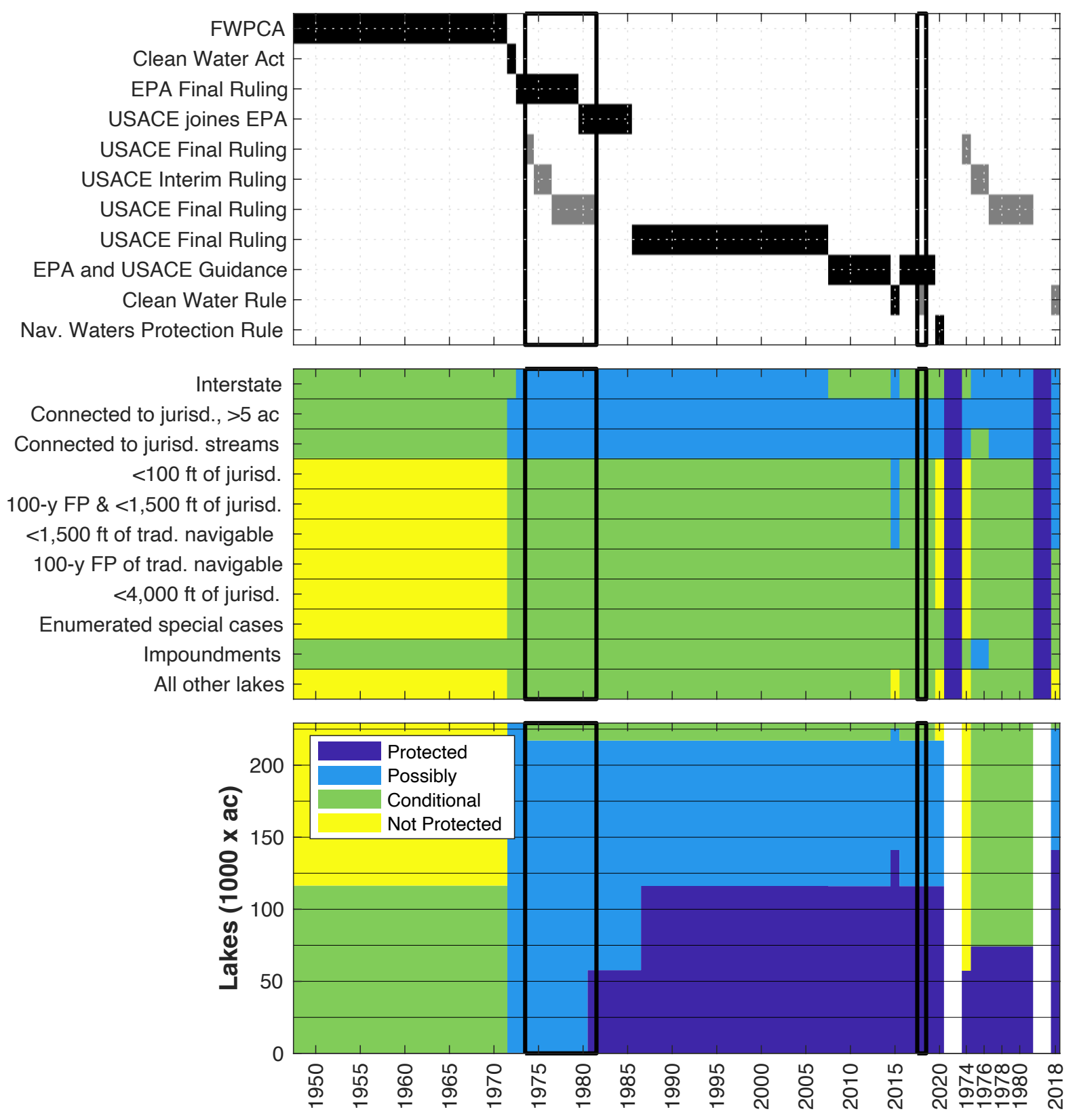

Fig. 4. Timeseries of actively enforced regulations and/or guidance (top), definitions used to designate jurisdictional status for lakes (middle), and 1000s of acres of jurisdictional lakes within the Wabash River Basin. Colors panels denote the jurisdictional status as a function of applicable definitions (middle) and the spatial extent of waters in each category (bottom). 


\subsection{Uncertainty due to competing regulatory programs}

From 1973 to 1982 the USEPA and USACE independently asserted competing jurisdictional definitions, contributing to the uncertainty already present in their definitions. Up until 1980, the USEPA definition resulted in nearly all streams and lakes falling into the possibly or conditionally jurisdictional categories, since their broad regulatory language could potentially capture all waters. In contrast, the USACE developed a more quantitative definition following Natural Resources Defense Council v. Callaway [18]. This definition included quantitative limits such as protections for all waters with discharge of $5 \mathrm{ft}^{3} / \mathrm{s}$, and adjacent lakes greater than five acres [19]. The specificity of the USACE definition resulted in greater definitively and fewer possibly jurisdictional streams and lakes during this time.

While the USEPA did not consider wetlands jurisdictional until 1980, the USACE began regulating wetlands "contiguous" to WOTUS in 1975. All other wetlands could be conditionally regulated if decided by the District Engineer, resulting in a large conditionally jurisdictional category. The 1977 USACE definition resulted in the movement of most of these wetlands from the conditionally to the possibly jurisdictional category, and this definition was closely matched by the USEPA in 1980.

In 2018, definitions diverged once again when the Clean Water Rule was restored across 26 states. This change did not impact the miles of regulated streams since ordinary high water mark was used to make jurisdictional determinations under both rules. This analysis shows, however that in states where the Clean Water Rule was enforced, more lakes and wetlands were definitively jurisdictional and more wetlands were not jurisdictional (Figs. 3-4).

\section{SYNTHESIS \& CONCLUSIONS}

\subsection{Uncertainty in jurisdiction has not been eliminated in $70+$ years of regulation}

While the geographic scope of WOTUS has expanded since 1948, uncertainty in exactly which waters are jurisdictional has remained high. Most streams, about half of lakes, and about one third of wetlands have consistently fallen into the "possibly" or "conditionally" jurisdictional categories since 1986 (Fig. 2-4). Supreme Court cases and agency rules aimed at clarifying one part of the WOTUS definition often shifted uncertainty and debate to another part, answering some regulatory questions while raising others. For example, while the significant nexus test was newly introduced in response to the Rapanos $v$. United States [27] decision and subsequent agency guidance [42], it does not influence the acres of "conditionally" jurisdictional wetlands at that point in time. The guidance removed conditional protections over all waters, "the use, degradation or destruction of which could affect interstate or foreign commerce," [25] but replaced that with conditional protections over waters with a "significant nexus" to WOTUS. The result was that, for the purposes of this analysis, the same area of water received conditional protections under either of these rules. The specific test to be applied in determining jurisdiction was the significant change, not the jurisdictional scope nor certainty.

Some shifts in uncertainty cannot be quantified using our approach. In the most recent attempt to reduce uncertainty, the 2020 NWPR functionally shifts uncertainty from wetlands to streams [72]. The rule scales back regulated wetlands to those immediately adjacent to WOTUS, sharing a continuous surface water connection. Streams, however, receive more complicated treatment. It is difficult to determine a quantitative range for waters that flow perennially or intermittently, as outlined in this rule. This analysis shows that most uncertainty arises from the definition of which streams are regulated, and that uncertainty in the stream network transfers to uncertainty over which lakes and wetlands are regulated. The NWPR may increase this range farther, since intermittent flow is left unquantified. Furthermore, the NWPR describes that these flow designations should be made in context of a "rolling 30-year window" [36]. This prospect further increases uncertainty, since climate change is currently altering stream networks and flow patterns across the country $[1,72]$.

\subsection{Historical changes to WOTUS provide context for modern rulemaking}

Modern changes to CWA jurisdiction, such as the NWPR and Clean Water Rule, have had relatively small impacts on jurisdictional scope and certainty compared to evolution since the inception of the 
1948 Federal Water Pollution Control Act. For example, wetlands have only been explicitly excluded from WOTUS twice since 1986. Under the 2015 Clean Water Rule, 2,410 acres in our study basin were determined to be "not" jurisdictional. However, 86,460 acres were also added to the "definitively" jurisdictional category, shrinking uncertainty from both directions and potentially increasingly efficient enforcement of regulations. While the 2020 NWPR also reduces uncertainty, it achieves this by removing at least 24,180 acres of wetland from federal protection, making it the largest exclusion since it was determined that wetlands could be WOTUS. Understanding this history provides context for modern changes and the associated political and legal divisiveness that accompany major environmental legislation.

\subsection{The agencies' role is to produce clear regulatory language and reduce uncertainty}

The vague definition of WOTUS in the 1972 CWA gave autonomy to the agencies to clarify which waters should be regulated. It is the agencies' role to reduce uncertainty in the administration of the act by implementing the law as informed by specialized topical knowledge [73]. Reduced uncertainty can simplify jurisdictional determinations, saving agency time and money. Field visits can be shorter, less clarifying communication with the permittee may be required, and there is a lower likelihood that the agency will have to defend a decision in the courts if precedent is firmly established. In our analysis, the 2015 Clean Water Rule was the most successful attempt to reduce regulatory uncertainty in the modern era, but was not implemented for long enough to realize these efficiencies.

Maintaining some uncertainty can also be beneficial, as it leaves more power to district staff and state agencies to adapt the law to their jurisdictions. Federal environmental laws provide blanket protection across a geographically and climatologically diverse country. Much like the agencies are assumed to have more detailed environmental knowledge than the legislature, state and local agencies might have better localized knowledge over the areas they regulate. Uncertainty left in the federal WOTUS definition allows states the freedom to adopt rules that best suit their environmental and political needs. Sometimes patchwork regulations are difficult for corporations and the federal government to follow, however, and there have been attempts to unify the state implementation strategies [69].

Ultimately, vague language may be an intentional mechanism to grant authority to the states in some cases, but in others it may be an expensive way to try for a different court ruling. If the agencies continue to diverge from established court decisions and fail to develop clear, quantifiable rules, then we expect to continue seeing WOTUS litigation in the courts [e.g., 5-7].

\subsection{Regionalization and transferability of results}

Our analysis of the Wabash drainage basin provides new insight into historical changes in Midwest WOTUS, but may not accurately represent changes across the country. Many region-specific features would have impacted the analysis if it were performed in a different basin, but the general approach of defining qualitative and quantitative limits and mapping jurisdictional scope can be replicated. For example, stream flow frequency and magnitude vary across the country, with flow patterns in mountainous and arid regions differing drastically from those found in the Midwest, especially for intermittently flowing waters [74]. In response, the agencies allow for region-specific guides for identifying ordinary high water marks. Under the new NWPR, new challenges will arise, since perennial flows are less common in arid regions, which may cause loss of protections for streams, lakes, and wetlands [75]

Other regions bear unique features that may have influenced the analysis if included. For example, the Clean Water Rule included conditional protections for Carolina and Delmarva bays, coastal prairie wetlands, prairie potholes, pocosins, and western vernal pools [47]. In regions with these features, the Clean Water Rule may have increased protections more than in our study basin where such features are not present. As a result, there may have been more "conditionally" or "not" jurisdictional waters seen during other time periods.

\subsection{On the role of geospatial analysis to evaluate policy implications}


This study is, to our knowledge, the first to consider the geographical scope of evolving laws, regulations, and court decisions in assessment of protections for streams, lakes, and wetlands in the U.S. While agencies have repeatedly declined to quantify the effect of modern rulemaking, citing uncertainty and data limitations $[39,50,76]$, we demonstrate here that quantitative estimates are plausible and informative. However, we do acknowledge that these maps provide only a preliminary assessment and actual permit decisions will require field studies in many cases. Moreover, we extend these analyses from modern estimates [1] to provide context in terms of the temporal evolution of jurisdiction and the source(s) of uncertainty. In reviewing the evolving regulatory landscape, it is clear that the series of laws, decisions, and rules reflect a persistent need for specificity in language and objective bases for enforcement. Finally, while our focus has been the U.S. Clean Water Act, the approach of translating polices to the on-the-ground implications is one that would be readily transferred to assess existing or proposed changes (e.g., for the European Water Framework).

\title{
Funding Information
}

Research was supported in part by NSF awards EAR-1652293, EAR-1331906, DEB-1754389, DoE award DE-SC0019377, the Indiana University Environmental Resilience Institute and Public Policy Institute, the Burnell and Barbara Fischer Fellowship, and the Institute of Advanced Studies at the University of Birmingham.

\section{Acknowledgments}

The authors thank R. Lave, R. Fischman, and N. Zirogiannis for input on early versions of this study and support in the analysis. A portion of Walsh and Ward's time was supported by the Burnell and Barbara Fischer Fellowship and Indiana University's Public Policy Institute. Finally, the authors note the views expressed in this study are those of the authors and do not reflect official positions of any agency.

\section{Conflict of Interest}

The authors have declared no conflicts of interest for this article.

\section{Author Contributions}

Walsh completed the initial literature review, data analysis, and drafted the first version of the manuscript. Ward conceptualized the project, secured funding for the research, and collaborated on data analysis. The authors contributed equally in writing the final version of the manuscript.

\section{Data Availability}

The spatial data sets generated from Walsh and Ward's original analysis [1] and a tabular summary of the information presented in Figs. 2-4 are available online in CUAHSI's HydroShare at:

http://www.hydroshare.org/resource/11f5d423318e47858bac5639af5be9de

Note to reviewers: After this article is assigned a DOI, the metadata for the data set will be updated and the data link will become

https://doi.org/10.4211/hs.11f5d423318e47858bac5639af5be9de

\section{ORCID}

Adam S. Ward https://orcid.org/0000-0002-6376-0061

\author{
Related WIREs Articles
}

An overview of the hydrology of non-perennial rivers and streams https://doi.org/10.1002/wat2.1504 


\section{References}

1. Walsh, R.; Ward, A.S. Redefining Clean Water Regulations Reduces Protections for Wetlands and Jurisdictional Uncertainty. Front. Water 2019, 1, 1-6.

2. $\quad$ Federal Water Pollution Control Act Amendments of 1972; 33 U.S.C. $\S \S 1251-1387,1972$;

3. $\quad$ Copeland, C. Clean Water Act: A Summary of the Law; 2016;

4. Mulligan, S.P. Evolution of the Meaning of "Waters of the United States " in the Clean Water Act; 2019;

5. Conservation Law Foundation, et al. v. Andrew Wheeler, et al.; 2020; p. Case No. 20-cv10820;

6. South Carolina Coastal Conservation League, et al. v. Andrew Wheeler, et al.; p. Case No. 2:20-cv-01687-DCN;

7. State of California, et al. v. Andrew Wheeler, et al.; pp. 20-cv-03005-RS;

8. Federal Water Pollution Control Act of 1948; 33 U.S.C. 1251 - 1376, 1948;

9. Barry, F. The Evolution of the Enforcement Provisions of the Federal Water Pollution Control Act: A Study of the Difficulty in Developing Effective Legislation. Michigan Law Rev. Assoc. 1970, 68, 1103-1130.

10. Federal Water Pollution Control Act Amendments of 1961; 1961;

11. Water Quality Act of 1965; 1965;

12. Water Pollution Control Act. J. Am. Water Work. 1948, 40, 899-906.

13. USEPA Wadeable Streams Assessment: A Collaborative Survey of the Nation's Streams 2006.

14. Survey, A.C. National Rivers and Streams Assessment 2013-2014: A collaborative survey; 2020;

15. Nixon, R. Veto of the Federal Water Pollution Control Act Amendments of 1972 Available online: https://www.presidency.ucsb.edu/documents/veto-the-federal-water-pollution-controlact-amendments-1972 (accessed on Mar 24, 2021).

16. USEPA National Pollutant Discharge Elimination System; 1973;

17. USACE Permits for Activities in Navigable Waters or Ocean Waters; 1974; p. 33 C.F.R. § 209.120;

18. Natural Resources Defense Council, Inc. v. Callaway; 1975; p. 392 F. Supp. 685;

19. USDOD Permits for Activities in Navigable Waters or Ocean Waters. Fed. Regist. 1975, 40, 31320-31343.

20. USDOD Navigation and Navigable Waters. Fed. Regist. 1977, 42, 37122-37164.

21. USEPA Consolidated Permit Regulations: RCRA Hazardous Waste; SDWA Underground Injection Control; CWA National Pollutant Discharge Elimination System; CWA Section 404 Dredge or Fill Programs; and CAA Prevention of Significant Deterioration. Fed. Regist. 1980, 45, 33424-.

22. Johnston, C.A. The Cumulative Effect of Wetlands on Stream Water Quality and Quantity. A Landscape Approach. Biogeochemistry 1990, 10, 105-141.

23. Johnston, C.A. Sediment and Nutrient Retention by Freshwater Wetlands: Effects on Surface Water Quality. Crit. Rev. Envrionmental Control 1991, 21, 491-565.

24. United States v. Riverside Bayview Homes; 1985; p. 474 US 121;

25. USDOD Final Rule for Regulatory Programs of the Corps of Engineers. Fed. Regist. 1986, 51, 41217-.

26. Solid Waste Agency of Northern Cook County v. U.S. Army Corps of Engineers; 2001; p. 531 US 159;

27. Rapanos v. United States; 2006; Vol. 547 US 715;

28. US EPA; US DoD Clean Water Act Jurisdiction Following the U.S. Supreme Court's Decision in Rapanos v . United States \& Carabell v . United States. 2008, Pub. L. 92, 1-13.

29. US EPA Connectivity of Streams \& Wetlands to Downstream Waters: A Review and Synthesis of the Scientific Evidence (Final Report); Washington, DC, 2015;

30. US DoD; EPA, U. Clean Water Rule: Definition of "Waters of the United States." Fed. Regist. 
2015, 80, 37054-37127.

31. State of Ohio, et al. v. U.S. Army Corps of Engineers, et al.; 2015; p. Case Nos. 153799/3822/3853/3887;

32. National Association of Manufacturers v. Department of Defense et al.; 2018; p. 583 US

33. USDOD; USEPA Definition of "Waters of the United States"'-Addition of an Applicability Date to 2015 Clean Water Rule. Fed. Regist. 2017, 82, 55542-55547.

34. USDOD; USEPA Definition of "Waters of the United States"'-Recodification of Pre-Existing Rules. Fed. Regist. 2019, 84, 56626-56671.

35. Trump, D. Executive Order 13778: Restoring the Rule of Law, Federalism, and Economic Growth by Reviewing the "Waters of the United States" Rule. Fed. Regist. 2017, 82, 1249712498.

36. USDOD; USEPA The Navigable Waters Protection Rule: Definition of "Waters of the United States." Fed. Regist. 2020, 85, 22250-22342.

37. US DoD Final Rule for Regulatory Programs of the Corps of Engineers. Fed. Regist. 1986, 51, 41206-41260.

38. Water Quality Act of 1987; 1987;

39. USEPA Mapping the Truth Available online: https://blog.epa.gov/2014/08/28/mapping-thetruth/ (accessed on Mar 24, 2021).

40. USDOD Final Notice of Issuance and Modification of Nationwide Permits. Fed. Regist. 2000, $65,12818-12899$.

41. USDOD; USEPA Advance Notice of Proposed Rulemaking on the Clean Water Act Regulatory Definition of "Waters of the United States."' Fed. Regist. 2003, 68, 1991-1998.

42. USEPA; USDOD Clean Water Act Jurisdiction Following the U.S. Supreme Court's Decision in Rapanos v. United States and Carabell v. United States.; 2008;

43. USACE; USEPA JURISDICTIONAL DETERMINATION FORM INSTRUCTIONAL GUIDEBOOK; 2007;

44. USACE CWA Guidance: HQ Field Memos Implementing the Rapanos Guidance [compendium of 34 decisions included as 'Other Supporting Documentation'] Available online: https://www.usace.army.mil/Missions/Civil-Works/Regulatory-Program-and-Permits/RelatedResources/CWA-Guidance/ (accessed on Mar 30, 2021).

45. USDOD PART 328-DEFINITION OF WATERS OF THE UNITED STATES; 2011;

46. USDOD PART 323-PERMITS FOR DISCHARGES OF DREDGED OR FILL MATERIAL INTO WATERS OF THE UNITED STATES; 2011;

47. USDOD; USEPA Clean water rule: definition of "waters of the United States". Fed. Regist. 2015, 80, 37054-37127.

48. USEPA; USDOD Proposed Revised Definition of "Waters of the United States": Key Proposed Changes Fact Sheet; 2018;

49. USEPA; USDOD Navigable Waters Protection Rule Fact Sheet: Overview of the Navigable Waters Protection Rule Available online: https://www.epa.gov/sites/production/files/202001/documents/nwpr_fact_sheet_-_overview.pdf (accessed on Mar 30, 2021).

50. USEPA; USDOD Navigable Waters Protection Rule Fact Sheet: Mapping and the Navigable Waters Protection Rule Available online: https://www.epa.gov/sites/production/files/202001/documents/nwpr_fact_sheet_-_mapping.pdf (accessed on Mar 24, 2021).

51. USEPA; USDOD Navigable Waters Protection Rule Fact Sheet: Implementing the Navigable Waters Protection Rule Available online: https://www.epa.gov/sites/production/files/202001/documents/nwpr_fact_sheet_-_implementation_tools.pdf (accessed on Mar 30, 2021).

52. USEPA; USDOD Navigable Waters Protection Rule Fact Sheet: Rural America and the Navigable Waters Protection Rule Available online: https://www.epa.gov/sites/production/files/2020-01/documents/nwpr_fact_sheet__rural_america.pdf.

53. USEPA; USDOD Navigable Waters Protection Rule Fact Sheet: "Typical Year" and the Navigable Waters Protection Rule Available online: https://www.epa.gov/sites/production/files/2020-01/documents/nwpr_fact_sheet__typical_year.pdf (accessed on Mar 30, 2021).

54. USEPA; USDOD Navigable Waters Protection Rule Photo Appendix Available online: https://www.epa.gov/sites/production/files/2020-01/documents/nwpr_fact_sheet_- 
_photo_appendix.pdf (accessed on Mar 30, 2021).

55. COUNTY OF MAUI, HAWAII v. HAWAII WILDLIFE FUND ET AL.;

56. USEPA; USDOD Resource and Programmatic Assessment for the Navigable Waters Protection Rule; 2020;

57. USEPA; USDOD Resource and Programmatic Assessment for the Navigable Waters Protection Rule Appendices; 2020;

58. USEPA; USDOD Economic Analysis for the Navigable Waters Protection Rule: Definition of "Waters of the United States"; 2020;

59. USDOD CWA Summary (Powerpoint Presentation Slides); 2007;

60. USEPA; USDOD Questions and Answers for Rapanos and Carabell Decision; 2007;

61. USEPA; USDOD Guidance Highlights for Rapanos and Carabell Decision; 2007;

62. USDOD Key Points for Rapanos and Carabell Decision; 2007;

63. Grumbles, B.H.; Woodley, Jr., J.P. U.S. Environmental Protection Agency (EPA) and U.S.

Army Corps of Engineers (Corps) Coordination on Jurisdictional Determinations (JDs) under Clean Water Act (CWA) Section 404 in Light of the SWANCC and Rapanos Supreme Court Decisions; 2007;

64. Grumbles, B.H.; Woodley, Jr., J.P. Clean Water Act Jurisdiction Following the U.S. Supreme Court's Decision in Rapanos v. United States \& Carabell v. United States; 2007;

65. Riley, D.T. MEMORANDUM FOR COMMANDER, MAJOR SUBORDINATE COMMANDS AND DISTRICT COMMANDS; 2008;

66. USEPA; USDOD Questions and Answers Regarding the Revised Rapanos \& Carabell Guidance; 2008;

67. USEPA; USDOD RESPONSE TO COMMENTS "CLEAN WATER ACT JURISDICTION FOLLOWING THE SUPREME COURT'S DECISION IN RAPANOS v. UNITED STATES \& CARABELL v. UNITED STATES GUIDANCE" ISSUED JUNE 5, 2007; 2007;

68. USDOD Part 322-PERMITS FOR STRUCTURES OR WORK IN OR AFFECTING NAVIGABLE WATERS OF THE UNITED STATES; 2011;

69. USGAO Waters and Wetlands: Corps of Engineers Needs to Evaluate its District Office Practices in Determining Jurisdiction; 2004;

70. Allen, G.H.; Pavelsky, T.M.; Barefoot, E.A.; Lamb, M.P.; Butman, D.; Tashie, A.; Gleason, C.J. Similarity of stream width distributions across headwater systems. Nat. Commun. 2018, 9, 610.

71. Downing, J.A.; Cole, J.J.; Duarte, C.M.; Middelburg, J.J.; Melack, J.M.; Prairie, Y.T.; Kortelainen, P.; Striegl, R.G.; McDowell, W.H.; Tranvik, L.J. Global abundance and size distribution of streams and rivers. Inl. Waters 2012, 2, 229-236.

72. Ward, A.S.; Walsh, R. New Clean Water Act Rule Leaves U.S. Waters Vulnerable. Eos (Washington. DC). 2020, 101.

73. Bach, T.; Niklasson, B.; Painter, M. The role of agencies in policy-making. Policy Soc. 2012, 31, 183-193.

74. Hammond, J.C.; Zimmer, M.; Shanafield, M.; Kaiser, K.; Godsey, S.E.; Mims, M.C.; Zipper, S.C.; Burrows, R.M.; Kampf, S.J.; Dodds, W.K.; et al. Spatial Patterns and Drivers of Nonperennial Flow Regimes in the Contiguous United States Geophysical Research Letters. Geophys. Res. Lett. 2021, 48, e2020GL090794.

75. USEPA Science Advisory Board Commentary on the Proposed Rule Defining the Scope of Waters Federally Regulated Under the Clean Water Act; 2020;

76. Letter from Nancy Stoner, Acting Assistant Adm'r, EPA Office of Water, to Lamar Smith, Chairman, Comm. on Science, Space, and Tech., U.S. House of Representatives (July 28, 2014) Available online:

https://web.archive.org/web/20180919173837/https:/science.house.gov/sites/republicans.scien ce.house.gov/files/documents/epa_releases_maps_letter.pdf (accessed on Mar 24, 2021). 